Same-Sex Peer Norms: Implications for Gender Differences in Negotiation

\author{
Selin Kesebir \\ London Business School \\ Sun Young Lee \\ UCL School of Management, University College London (UCL) \\ Judy Qiu \\ London Business School \\ Madan Pillutla \\ London Business School
}




\begin{abstract}
Starting in early childhood, girls and boys segregate into same-sex groups and create distinct peer cultures with different norms. Girls tend to form intimate dyadic bonds while boys interact in larger groups, in which they compete for rank. Girls rarely engage in group activities or openly compete against each other. Instead, female peer culture values harmony and the appearance of equality. These differences in peer culture may have implications for women's negotiations because they prescribe certain norms on relating to others and coping with competition and conflict. In this chapter, we review differences in female and male peer relationships, and discuss the ways these differences could manifest themselves in negotiations.
\end{abstract}




\section{Same-Sex Peer Norms: Implications for Gender Differences in Negotiation}

Across cultures, young girls and boys segregate into same-sex groups and create distinct peer cultures (Maccoby \& Jacklin, 1987; Munroe \& Romney, 2006; Whiting \& Edwards, 1988). Beginning at around age 3, children are increasingly drawn to same-sex peers (La Freniere, Strayer, \& Gauthier, 1984; Ruble \& Martin, 1998). Consequently, they spend substantially more time with same-sex peers. For example, Maccoby and Jacklin (1987) reported that 61/2-year-olds interacted with same-sex peers about 11 times more often than they did with other-sex peers. These largely sex-segregated childhood experiences constitute powerful socialization contexts and can be labelled as distinct "cultures" (Maccoby, 1990; Maltz \& Borker, 1982). Like all cultures, they promote specific norms, social concerns, and skills.

Our premise in this chapter is that these gendered peer cultures may offer some insights into how women and men conduct themselves in economic and organizational spheres in adulthood, particularly when they interact with same-sex peers. For three reasons, we expect that behavior in adulthood will be aligned with the same-sex peer culture norms originating in childhood (Leaper, 1994; Thorne \& Luria, 1986). First, the factors that lead to the emergence of these distinct peer cultures (such as evolved gender differences or distinct socialization experiences) are likely to last through adulthood as well—at least in part. This means that behavior in adulthood would be shaped by enduring factors that shaped behavior in childhood. Second, distinct peer cultures mean that the two genders have been trained and rewarded for distinct cognitive and behavioral tendencies. These acquired skills and preferences are likely to stay and shape behavior in adulthood (Grusec \& Hastings, 2007; Whiting \& Edwards, 1988). Third, people follow cultural norms eagerly and those who do not are often subjected to social sanctions (Cialdini \& Trost, 1998). Adult females and males are thus likely to follow these norms, unless the norms expire at some point during 
development. A norm is most binding, and its violation most problematic, when interacting with members of the same culture (Abrams, Marques, Bown, \& Henson, 2000; Marques \& Yzerbyt, 1988; Terry \& Hogg, 1996). For this reason, same-sex peer norms should be most applicable when interacting with same-sex peers.

To our knowledge, gendered peer cultures have not been proposed as a potential source of gender differences in negotiations. Existing theoretical accounts on this question have invoked, among others, status characteristics (Miles \& Clenney, 2010), social power (Watson, 1994; Small, Gelfand, Babcock, \& Gettman, 2007), relational self-construals (Curhan, Neale, Ross, \& Rosencranz-Engelmann, 2008; Gelfand, Major, Raver, Nishii, \& O’Brien, 2006), and gender roles with their concomitant gender stereotypes (e.g., Amanatullah \& Morris, 2010; Bear \& Babcock, 2012; Bowles, Babcock, \& Lai, 2007; Kray \& Thompson, 2005; for a review see Stuhlmacher \& Linnabery, 2013). We believe that gendered peer cultures offer a complementary perspective to these accounts and provide a theoretically driven agenda for empirical research on gender differences in negotiation. This research agenda may be particularly useful in explaining how negotiation dynamics are shaped by the gender composition of the negotiators - a topic in need of further theoretical development (Kray \& Thompson, 2005).

\section{How are Male and Female Peer Cultures Different?}

Researchers who have studied same-sex peer interactions noted some emerging properties in these interactions (Maccoby, 1990). Even though behavioral differences were minimal when girls and boys were observed individually, a group of girls acted quite differently from a group of boys. In the following, we will describe some of these differences in childhood peer cultures and highlight continuities into adolescence, young adulthood, and adulthood. Our review is not exhaustive - we instead focus on three broad themes that may have implications for negotiations. For each theme, we first describe the supporting empirical 
evidence and then its implications for negotiations. Many of the implications we discuss are potential disadvantages for women in negotiations. Our goal is to raise awareness of these potential disadvantages in order to stimulate research, so that we can eventually help women improve their negotiation performance and feel more comfortable before, during and after negotiations. Raising awareness and creating change intentions is an effective step toward behavioral change (Webb \& Sheeran, 2006).

\section{Difference 1: Males are More Strongly Oriented toward Larger Groups than are Females}

Convergent evidence from social and developmental psychology has shown that men are more strongly oriented toward larger collectives than are females (Baumeister \& Sommer, 1997; Geary, Byrd-Craven, Hoard, Vigil, \& Numtee, 2003; Gabriel \& Gardner, 1999; Van Vugt, De Cremer, \& Janssen, 2007). This gender difference is manifest in both behavioral patterns and psychological characteristics.

From around 5-6 years of age, boys play in larger groups than do girls (Belle, 1989; Benenson, Apostoleris, \& Parnass, 1997; Lever, 1978; Maccoby, 1988; Maccoby, 2002). In one questionnaire of $10-11$ year-old children, $72 \%$ of boys, compared to $52 \%$ of girls, stated that their neighborhood games usually included four or more persons (Lever, 1976). Observations reveal even larger differences in play group size: In her study of 10-11 year-old children in three US schools, Lever (1978) observed that during recess boys often played team sports such as basketball or football involving ten to twenty-five boys. Girls, in contrast, often played games such as tag, dancing, or jump rope, which required no more than 2-3 players and seldom involved more than five or six. Girls also often engaged in parallel activities such as riding their bikes together, which did not require coordination among players.

This difference in same-sex play patterns may serve distinct needs of females and males in terms of survival and reproduction. Play in humans and other animals helps with 
practicing and refining the competencies necessary for survival and reproduction (Fagen, 1981; Smith, 1982). In this light, boys' play appears to hone skills necessary to form and maintain successful large-scale coalitions that will have a competitive advantage over other coalitions in intergroup competition (e.g., Carvajal-Carmona et al., 2000). These types of skills would confer an advantage in collective endeavors such as hunting or warfare, which are conducted by coalitions of males across cultures and have enormous stakes for survival and reproduction (Tiger, 1969). On the other hand, girls' play appears to hone skills for forming and maintaining dyadic relationships.

If maintaining larger groups confers relatively higher survival and reproduction advantages on males compared to females, males should be more open than females to accepting newcomers into their groups and be less exclusive in peer relations. Empirical evidence supports this prediction. Girls are more likely than boys to form dyadic relationships with same-sex peers, rather than building larger friendship circles — at least after preschool years (Buhrmester \& Prager, 1995; Savin-Williams, 1980a). A sociometric study of fifth- and sixth-graders asked girls and boys to name as many of their best friends from their class as they wanted (Eder \& Hallinan, 1978). Pairs of girls who had nominated each other as best friends were less likely than pairs of boys to nominate a third person as another best friend. Girls' friendship dyads were thus more exclusive. In another study with first-graders, a new child was introduced to a pair of same-sex children who had already met and played together in the lab a week ago (Fesbach, 1969). Girls initially displayed significantly more excluding and rejecting behaviors toward the new child, although the difference was not statistically significant toward the end of the play period (Fesbach, 1969).

Similar patterns have been observed in adolescents. In one study, a pair of same-sex friends from the eighth grade were joined by another same-sex student from the seventh grade to discuss social problems and come up with solutions (Fesbach \& Sones, 1971). 
Compared to boys, girls took longer to speak to the newcomer and were less likely to incorporate the newcomer's ideas into the final solution. They also judged the newcomer more negatively in terms of traits such as intelligence, appearance, and leadership. Finally, at a camp for 8-15 year old children, boys' friendship networks became more interconnected over time than girls' networks, presumably because their friends were more likely to become friends with one another while girls' networks became gradually less interconnected (Parker $\&$ Seal, 1996).

The higher exclusivity of girls' relationships compared to boys' may be partly explained by the higher levels of intimacy that characterizes female relationships (Dindia \& Allen, 1992; Rose \& Rudolph, 2006; Shulman, Laursen, Kalman, \& Karpovsky, 1997). Females disclose more personal information to each other, provide more emotional support, and offer more guidance in dealing with interpersonal or other problems. These friendship norms may constrain the number of female friendships as they require high levels of investment. Females also report more jealousy over their close friends' actual or anticipated relationships with other girls, and more jealousy-driven surveillance, implying stronger expectations and desire for exclusivity in their relationships (Lavallee \& Parker, 2009; Parker, Low, Walker, \& Gamm, 2005).

Research finds some continuity in same-sex interaction patterns from childhood into adulthood, with males being relatively more oriented toward larger groups and females toward dyadic relationships (e.g., Arndt, Greenberg, \& Cook, 2002; Baumeister \& Sommer, 1997; Gabriel \& Gardner, 1999; Gardner \& Gabriel, 2004). Men are more likely to describe themselves in terms of collectives, such as fraternities or ethnicities, whereas women are more likely to define themselves in terms of their important dyadic relationships, such as being a best friend or daughter (Gabriel \& Gardner, 1999). When asked to remember a sad or happy experience, men are more likely than women to report an experience concerning a 
collective identity, such as being a fan of a sports team. Compared to women, men also more often recall events from a fictitious diary if the event involves a collective identity (Gabriel \& Gardner, 1999). Further support for the relative weights women and men put on groups vs. dyadic relationships comes from research that reminds people of their own mortality. This body of research has found that when reminded of their own death, people tend to endorse central elements of their worldview more strongly (Greenberg, Solomon, \& Pyszczynski, 1997). When college students were primed with death, nationalistic constructs became more accessible for men, and romantic constructs more accessible for women, suggesting that national identity is more central to men's worldview than to women's and romantic relationships more central to women's worldview than men's (Arndt, Greenberg, \& Cook, 2002).

\section{Implications for Negotiations}

Altogether, these findings show that men are more strongly oriented toward larger groups, and from early childhood on, they accumulate more experiences in functioning within collectives that work toward a collective goal (such as outcompeting a rival group). Women, on the other hand, are more experienced in forming and maintaining exclusive and intimate dyadic relationships. What are some implications of these patterns for women's and men's negotiation behaviors?

One direct implication concerns negotiations involving multiple parties. By virtue of interacting within larger groups, boys are more likely to develop the skills for exerting influence and getting one's way in such settings. In a larger group, voicing one's interests (or being assertive) is required for getting heard one's needs and desires (Benenson et al., 2002a). Given their greater experience in larger groups compared to females, we expect males to be more willing to enter multi-party negotiations, more comfortable with asserting their own interests in these negotiations, and more skilled in exerting influence in them. Their 
greater experience in large groups may also give men an advantage over women in mixed-sex multi-party negotiations and allow them to obtain better average outcomes than females.

Another crucial aspect of multi-party negotiations is coalitional dynamics (Lax \& Sebenius, 1991). The ability to form alliances is necessary for success in multi-party negotiations. The greater female preference for and experience in exclusive relationships suggest that women may have stronger skills in forming dyadic alliances. At the same time, the exclusivity norm in female relationships may turn into a liability if it inhibits women from extending their coalitions beyond the dyad when larger coalitions would help them. The loyalty requirement of such relationships may also supply women a reliable coalition partner in settings with repeated negotiations, such as the workplace. Yet, the same loyalty requirements may cost women flexibility when their interests do not overlap with their female ally's. If loyalty and alignment is demanded from female friends on every issue, women may feel forced to choose between their friendships and other interests. Men, on the other hand, may be more able to shift alliances without endangering their relationships.

Gender differences in the experience and skills to maintain larger groups may also affect process and outcomes in intergroup negotiations (e.g., M\&A deals). For example, the relative female disadvantage in functioning within larger groups may prevent women from building effective negotiation teams. In one field study, all-female teams were outperformed by all-male or mixed teams in a team decision making task (Apesteguia, Azmat, \& Nagore, 2012). While this study concerned group decision-making and needs to be replicated in other contexts, it suggests that all-female negotiation teams may have a disadvantage in coordinating among multiple group members and coming to collective decisions. At the same time, women's greater proclivity for dyadic relationships may give them an advantage when negotiating as a two-person team, as they are good at building cohesion in a dyad. 


\section{Difference 2: Hierarchy and Competition are More Acceptable in Male Peer Relationships}

We have already noted that males are more likely to engage in inter-group competition. Not only do groups of men compete against other groups, but within these groups men also overtly compete with one another. Males are on average more likely than females to describe themselves as competitive (Lynn, 1993; Spence \& Helmreich, 1983) and are more willing to compete on various tasks (Flory, Leibbrandt, \& List, 2014; Niederle \& Vesterlund, 2011). This gender difference has been observed across the age spectrum, from kindergarten children to older adults (Ahlgren \& Johnson, 1979; Mayr, Wozniak, Davidson, Kuhns, \& Harbaugh, 2012; Sutter \& Glätzle-Rützler, 2014; Sutter, Glätzle-Rützler, Balafoutas, \& Czermak, 2016). Research with young and old adults also shows that males engage more in competitive team sports in the U.S. than do females (Deaner et al., 2012).

Consistent with the gender difference in competitive attitude and behaviors, competition is more acceptable within the male peer culture than it is in the female peer culture. Girls instead try to maintain harmony and the appearance of equality in their groups (for a review, see Campbell, 2013: Chapter 4). Competition and the resultant rankings are thus less acceptable within the female peer culture. One study with kindergarten children and fourth graders found that girls regarded competition with their same-sex peers as more uncomfortable than did boys (Benenson et al., 2002b). In another study with grade 8-10 students, girls reported more negative feelings than boys in response to outperforming their same-sex friends in academics and romance (Benenson \& Schinazi, 2004). Moreover, girls in this study reported feeling significantly happier when they obtained equal outcomes as their same-sex peers, as opposed to better outcomes, whereas the difference was not significant for boys. Finally, some evidence suggests that young girls who display competitiveness or claim superiority are disliked by their female peers. In her ethnographic study of children, Goodwin (1990) observed: 
Boys seem to openly encourage statements about relative rank in pastimes (although they of course may argue about them). However, a girl who positively assesses herself or explicitly compares herself with others may be seen as showing character and attitudes that the other girls find offensive. (p. 44)

Research documents continuity from childhood into adulthood. In the workplace, women regard competition with their same-sex coworkers less desirable and acceptable than do men, and competition hurts the relationship between two female coworkers more than the relationship between two male coworkers (Lee, Kesebir, \& Pillutla, 2016). Moreover, women who were put into competition with each other expressed lower levels of liking for each other, compared to men who had been put into competition.

One form of competition is competition for prestige and social power. This type of competition results in the formation of dominance hierarchies in groups. Male groups tend to quickly form relatively stable dominance hierarchies, as demonstrated in studies of boys at summer camp (Savin-Williams, 1976; 1979; 1980b). Girls in a summer camp setting also were found to have some hierarchical differentiation, but theirs was more fluid and situationspecific (Savin-Williams, 1979).

Males also seem to have stronger awareness of status differences in their groups. Lever (1978) reported that when asked "Who are the fifth-grade leaders?" boys pointed to the best athletes and team organizers as the rightful holders of the title. Girls, on the other hand, often hesitated before responding, then named peers with power but offered aggression rather than valuable skills as the explanation. Girls were also more likely to call their peers with power "bossy" or "big mouth." In other words, leadership did not have a positive connotation for fifth-grade girls, and they did not consider it a valuable or desirable quality. Research on social dominance orientation finds that men have a stronger preference for hierarchies than 
do women (Sidanius, Levin, Liu, \& Pratto, 1999), suggesting that this gender difference in attitudes about competition and hierarchies carry into adulthood.

In sum, female peer groups are less comfortable with competitive situations and less disposed to hierarchical differentiation than males. This gender difference in the norms around competition and the acceptance of hierarchies may be traced to the larger size of male groups and their pursuit of collective goals. The larger the group, the harder it is to maintain equality among group members. Moreover, a lack of differentiation may undermine success when pursuing collective goals (Ronay, Greenaway, Anicich, \& Galinsky, 2012). Hierarchies serve collective success by motivating performance, increasing the predictability and stability in social interactions, reducing conflict, and helping with coordination, even though they also have some costs (Anderson \& Brown, 2010; Halevy, Chou, \& Galinsky, 2011). In the absence of collective goals, female groups may not have much use for hierarchies.

\section{Implications for Negotiations}

The greater male tendency to compete with same-sex peers and create hierarchies has implications for negotiations because all negotiations have a competitive (i.e., distributive) component. Even if negotiators can create value and grow the pie during a negotiation, at the end, the created value needs to be distributed among the negotiators. This distribution is competitive in the sense that one party's gain is another's loss. Such a negative correlation of outcomes is at odds with female relational norms, which stress the importance of equality and harmony (cf. Lee et al., 2016). On this basis, we would expect that women would be less comfortable than men with engaging in negotiations with same-sex peers. Supporting this prediction, one study found that women were less likely to initiate a negotiation with a female partner than with a male partner, but no such difference was observed for men (Eriksson \& Sandberg, 2012). 
Women's discomfort with same-sex competition may manifest itself not only as a reluctance to enter distributive negotiations with other women. During a negotiation with another woman, it may surface as a desire to end the negotiation quickly and amicably, possibly by conceding more and settling on an outcome before exploring alternative options that could produce mutual gain. Moreover, after a negotiation, women may experience more relational strain with their same-sex peers than do men.

We would expect these proposed effects before, during, and after negotiations to be stronger to the extent that the negotiators perceive the negotiation as zero-sum. Furthermore, we would expect them to be amplified when the two women already have relational bonds or expect to have them going forward. This is because the peer norms that govern relational conduct may be seen as less relevant in one-off interactions but more binding in existing relationships. Put differently, female and male negotiator pairs may be more alike when they do not expect to interact with another in the future.

We have mentioned that women are less likely to build hierarchical relationships and instead desire to maintain the appearance of equality. This may make negotiations among women more uncomfortable if the exchange is not on equal footing. The deviation from equality may be due to hierarchical differences, such as when a female employee negotiates with her female boss about her salary, or due to power differences, such as when one female has a better alternative to a negotiated deal than her female counterpart. A female desire not to flaunt one's hierarchical position or power against another woman could lead women in more powerful positions to concede more against another woman than they would against a man, and more than a man in a similar position would concede against another man. 
Difference 3: Male Peer Relationships Have a Higher Threshold and More Tolerance for

\section{Conflict}

We have seen that males are more likely to interact in larger groups and engage in competition against other groups. To be effective at intergroup competition, these groups need to be robust to internal conflict. Numerically, a larger group implies a greater potential for interpersonal tensions among members which can get in the way of collective goals. These tensions can divide the group, affect its performance, and even dissolve it. To build successful groups then, males should effectively curtail conflict and bar its negative effects on group functioning. Some empirical research indeed suggests that males have a higher threshold for conflict and greater conflict-tolerance in their same-sex relationships than do females.

Multiple studies have found that boys' same-sex friendships are more stable and less fragile than girls' (Benenson \& Alavi, 2004; Benenson \& Christakos, 2003; Bowker, 2011; Hardy, Bukowski, \& Sippola, 2002). For example, in a study of 6th graders, girls reported more frequent dissolution of best friendships than did boys (Bowker, 2011). Similar results were obtained in a study that covered all grades from 1 to 6 and drew on observer reports in addition to the children's self-reports (Benenson \& Alavi, 2004). In another study of 10-15 year olds, $36 \%$ of girls, but only $17 \%$ of boys, reported that their closest same-sex friend had already done something to hurt their friendship, even though girls' friendships were on average more recently formed than boys' (Benenson \& Christakos, 2003). Finally, a study of college students found that male roommates were twice as likely as female roommates to say that they were satisfied with their same-sex roommates - that is presumably why female students switched their roommates more often than did male students (Benenson, et al., 2009). 
These findings may seem surprising in light of the evidence that females are the more agreeable, relationally-oriented, and harmony-seeking gender (Parker \& Asher, 1993; Rose \& Rudolph, 2006). We know that girls are keener to avoid conflict and use more polite and indirect forms of influence, which reduce the potential for conflict (Maltz \& Borker, 1982; Miller, Danaher \& Forbes, 1986; Weiss \& Sachs, 1991). Girls across the age spectrum also say that they are more concerned with potential or actual conflicts with their friends and invest more in repair attempts (Parker \& Asher, 1993). Given all this, why are female friendships more fragile than male friendships?

Empirical work offers some insights into this apparent puzzle: Girls have higher friendship expectations from each other than do boys, and relationships often break down when these high expectations are not met. We have already seen that girls demand more intimacy and exclusivity in their relationships with each other, and they experience more jealousy over friendships (Lavallee \& Parker, 2009; Parker et al., 2005). Other research with seventh- and eighth-graders shows that girls had greater expectations for commitment, loyalty and empathetic understanding from their friends than did boys (Clark \& Ayers, 1993). In another study, fourth- and fifth-grade children read vignettes in which their same-sex friends hypothetically engaged in various friendship violations - they betrayed them, were unreliable, or failed to provide support, validation or help (MacEvoy \& Asher, 2012). Girls in this study were more likely than boys to believe that their friend engaged in these behaviors because she did not care about or respect them, or because she wanted to control them. They also considered these transgressions to be more severe than did boys, anticipated experiencing significantly more anger and sadness, and said that they would be more likely to be thinking about the incidents a week later. Altogether, these findings suggest that girls set the friendship bar higher than males: They have higher expectations from their friends and they are more sensitive to violations of these expectations. 
We would like to stress, however, that this reaction seems to be specific to violations of friendship expectations, and not to other types of clashes in interests, needs, or desires. In fact, research that looked into minor conflicts of interests or desires (such as which game to play) among $4^{\text {th }}$ and $5^{\text {th }}$ graders found that boys were more likely to adopt hostile or assertive strategies than girls, and girls were more likely to adopt accommodating and compromising strategies that serve relationship-maintenance goals (Rose \& Asher, 1999). While females seem to be more concerned with relationship maintenance, they also expect more from their same-sex friends. This may explain why their friendships are more likely to dissolve than boys' friendships, despite girls' stronger motivation and efforts to maintain them.

\section{Implications for Negotiations}

The reviewed findings on conflict in same-sex peer relationships have some implications for negotiations. As we have seen, all negotiations have a competitive element, which may pose difficulties for women negotiating with other women. This competitive element may create conflict and sometimes even threaten the relationship. If women are less tolerant of conflict with their same-sex peers than are men, as the reviewed findings suggest, they may also be reluctant to act in ways that will trigger or intensify conflict with them. For example, they may refrain from pushing on issues that may cause conflict. This is what Bowles and Flynn (2010) found: In their studies, women were more likely to stand their ground and be assertive with male naysayers in a negotiation than they were with female naysayers. Importantly, participants were not negotiating with their friends in these studies, suggesting that our predictions may hold for strangers as well, even though we derived them from studies of friends. While only empirical investigation can resolve the moderating role of relational bonds, based on these results, we may surmise that the predicted effects could emerge in their absence. 
The reviewed work also highlights the need to differentiate among different types of issues when considering gender differences in negotiation. We have seen that females were generally more willing to compromise with their same-sex peers on various needs and desires, unless the relationship itself was the issue (MacEvoy \& Asher, 2012; Rose \& Asher, 1999). We may expect a similar dynamic in negotiations with same-sex peers such that women may be willing to compromise on instrumental issues as long as they can count on a positive relationship, characterized by mutual trust and goodwill. However, if the counterpart deviates from the code of positive relationships, women may be less forgiving and more prone to exit the negotiation, and even the relationship, because they have little tolerance for relational violations. On this basis, we would expect women to experience a stronger "chilling effect" (Pruitt, 1981) than men in response to a same-sex negotiator who is perceived to play hardball, because playing hardball is a clear indication that one does not have the other's interests at heart, and is thus a violation of relational norms.

\section{Conclusion}

We have proposed that an examination of gendered peer cultures in childhood and adolescence can provide insights into gender differences in negotiations. To uncover these insights, we have reviewed findings from developmental psychology $-\mathrm{a}$ field that has not yet been mined for insights into negotiations.

We consider same-sex peer cultures as one of the factors shaping gender dynamics in negotiations, but we do not consider it a rival of or a substitute for other factors proposed so far, such as gender stereotypes, power dynamics, or relational self-construals (e.g., Curhan et al., 2008, Stuhlmacher \& Linnabery, 2013). We expect that same-sex peer norms work in tandem with these other factors - sometimes reinforcing and sometimes counteracting them. A better understanding of gender differences in negotiation requires us to synthesize multiple perspectives. The additional value of the approach we described in this chapter is its ability to 
offer theoretically-based predictions on how the negotiation process and outcomes may depend on the gender composition of the negotiators.

We also suggested some factors which may moderate the extent to which same-sex peer norms will be operating in negotiations between women. First, we noted that the effects may be stronger when the negotiation partners already have relational bonds or expect to have them in the future. Second, we suggested that the effects may be stronger to the extent that the negotiation will be perceived as zero-sum because such open antagonism is anathema to female-female relationship norms. A third factor that might moderate the effect of samesex peer norms in negotiations is the applicability of other norms which can take situational precedence. For example, people negotiating on behalf of their organizations or clients may follow professional norms governing such interactions, as their primary group identification in such settings would be their organization rather than their gender. We thus expect that situationally activated norms would limit the reach of same-sex peer norms.

Previous research has studied national culture as a factor in negotiations (Gunia, Brett, \& Gelfand, 2016). In this chapter, we suggested that gender may also be fruitfully considered a "culture." Such a conceptualization allows us to make some predictions on gender effects in negotiations. These predictions are conjectural, and we presented them as hypotheses to be tested. They await empirical research to corroborate, qualify, or reject them. We hope that future research will test these hypotheses, along with their proposed moderators, such as the strength and prospects of the relationship with the negotiation partner, the zero-sum perceptions of the negotiation, and the availability of countervailing norms. 


\section{References}

Abrams, D., Marques, J. M., Bown, N., \& Henson, M. (2000). Pro-norm and anti-norm deviance within and between groups. Journal of Personality and Social Psychology, 78, 906-912.

Ahlgren, A., \& Johnson, D. W. (1979). Sex differences in cooperative and competitive attitudes from the 2nd through the 12th grades. Developmental Psychology, 15, 45-49.

Amanatullah, E. T., \& Morris, M. W. (2010). Negotiating gender roles: gender differences in assertive negotiating are mediated by women's fear of backlash and attenuated when negotiating on behalf of others. Journal of Personality and Social Psychology, 98, $256-267$.

Anderson, C., \& Brown, C. E. (2010). The functions and dysfunctions of hierarchy. Research in Organizational Behavior, 30, 55-89.

Apesteguia, J., Azmat, G., \& Iriberri, N. (2012). The impact of gender composition on team performance and decision making: evidence from the field. Management Science. 58, 78-93.

Arndt, J., Greenberg, J., \& Cook, A. (2002). Mortality salience and the spreading activation of worldview-relevant constructs: Exploring the cognitive architecture of terror management. Journal of Experimental Psychology-General, 131, 307-324.

Baumeister, R. F., \& Sommer, K. L. (1997). What do men want? Gender differences and two spheres of belongingness: Comment on Cross and Madson (1997). Psychological Bulletin, 122, 38-44.

Bear, J. B., \& Babcock, L. (2012). Negotiation topic as a moderator of gender differences in negotiation. Psychological Science, 23, 743-744. 
Belle, D. (1989). Gender differences in children's social networks and supports. In D. Belle (Ed.), Children's social networks and social supports (pp. 173-188). New York, NY: Wiley.

Benenson, J. F., \& Alavi, K. (2004). Sex differences in children's investment in same-sex peers. Evolution and Human Behavior, 25(4), 258-266.

Benenson, J. F., Apostoleris, N. H., \& Parnass, J. (1997). Age and sex differences in dyadic and group interaction. Developmental Psychology, 33, 538-543.

Benenson, J. F., \& Christakos, A. (2003). The greater fragility of females' versus males' closest same-sex friendships. Child Development, 74(4), 1123-1129.

Benenson, J. F., Maiese, R., Dolenszky, E., Dolensky, N., Sinclair, N., \& Simpson, A. (2002a). Group size regulates self-assertive versus self-deprecating responses to interpersonal competition. Child Development, 73(6), 1818-1829.

Benenson, J. F., Markovits, H., Fitzgerald, C., Geoffroy, D., Flemming, J., Kahlenberg, S. M., \& Wrangham, R. W. (2009). Males' greater tolerance of same-sex peers. Psychological Science, 20(2), 184-190.

Benenson, J. F., Roy, R., Waite, A., Goldbaum, S., Linders, L., \& Simpson, A. (2002b). Greater discomfort as a proximate cause of sex differences in competition. MerrillPalmer Quarterly, 48, 225-247.

Benenson, J. F., \& Schinazi, J. (2004). Sex differences in readctions to outperforming samesex friends. British Journal of Developmental Psychology, 22, 317-333.

Bowker, J. C. (2011). Examining two types of best friendship dissolution during early adolescence. Journal of Early Adolescence, 31(5), 656-670.

Bowles, H. R., Babcock, L., \& Lai, L. 2007. Social incentives for gender differences in the propensity to initiate negotiations: Sometimes it does hurt to ask. Organizational Behavior and Human Decision Processes, 103(1): 84-103. 
Bowles, H. R., \& Flynn, F. (2010). Gender and persistence in negotiation: A dyadic perspective. Academy of Management Journal, 53(4), 769-787.

Buhrmester, D., \& Prager, K. (1995). Patterns and functions of self-disclosure during childhood and adolescence. In K.J. Rotenberg (Ed.), Disclosure processes in children and adolescents. Cambridge, England: Cambridge University Press.

Campbell, A. (2013). A mind of her own: The evolutionary psychology of women. Oxford, England: Oxford University Press.

Carvajal-Carmona, L. G., Soto, I. D., Pineda, N., Ortíz-Barrientos, D., Duque, C., OspinaDuque, J., \& Ruiz-Linares, A. (2000). Strong Amerind/white sex bias and a possible Sephardic contribution among the founders of a population in northwest Colombia. American Journal of Human Genetics, 67(5), 1287-1295.

Cialdini, R. B., \& Trost, M. R. (1998). Social influence: Social norms, conformity, and compliance. In D. T. Gilbert, S. T. Fiske, \& G. Lindzey (Eds.), The handbook of social psychology (pp. 151-192). New York, NY: McGraw-Hill.

Clark, M. L., \& Ayers, M. (1993). Friendship expectations and friendship evaluations: reciprocity and gender effects. Youth \& Society, 24(3), 299-313.

Curhan, J. R., Neale, M. A., Ross, L., \& Rosencranz-Engelmann, J. (2008). Relational accommodation in negotiation: effects of egalitarianism and gender on economic efficiency and relational capital. Organizational Behavior and Human Decision Processes, 107(2), 192-205.

Deaner, R. O., Geary, D. C., Puts, D. A., Ham, S. A., Kruger, J., Fles, E., Winegard, B., \& Grandis, T. (2012). A sex difference in the predisposition for physical competition: males play sports much more than females even in the contemporary U.S. PLoS ONE 7(11): e49168. 
Dindia, K., \& Allen, M. (1992). Sex differences in self-disclosure: A meta-analysis. Psychological Bulletin, 112(1), 106-124.

Eder, D., \& Hallinan, M. T. (1978). Sex differences in children's friendships. American Sociological Review, 43(2), 237-250.

Eriksson, K. H., \& Sandberg, A. (2012). Gender differences in initiation of negotiation: Does the gender of the negotiation counterpart matter? Negotiation Journal, 28(4), 407428.

Fagen, R. M. (1981). Animal play behavior. Oxford, England: Oxford University Press.

Feshbach, N. D. (1969). Sex differences in children's modes of aggressive responses toward outsiders. Merrill-Palmer Quarterly of Behavior and Development, 15(3), 249-258.

Feshbach, N., \& Sones, G. (1971). Sex differences in adolescent reactions toward newcomers. Developmental Psychology, 4, 381-386.

Flory, J. A., Leibbrandt, A., \& List, J. A. (2014). Do competitive workplaces deter female workers? A large-scale natural field experiment on job-entry decisions. Review of Economic Studies, 82, 122-155.

Gabriel, S., \& Gardner, W. L. (1999). Are there "his" and "hers" types of interdependence? The implications of gender differences in collective versus relational interdependence for affect, behavior, and cognition. Journal of Personality and Social Psychology, $77(3), 642-655$.

Gardner, W. L., \& Gabriel, S. (2004). Gender differences in relational and collective interdependence: Implications for self-views, social behavior, and subjective wellbeing. In A. H. Eagly, A. E. Beall, \& R. J. Sternberg (Eds.), The psychology of gender (2nd ed., pp. 169-191). New York, NY: Guilford Press.

Geary, D. C., Byrd-Craven, J., Hoard, M. K., Vigil, J., \& Numtee, C. (2003). Evolution and development of boys' social behavior. Developmental Review, 23(4), 444-470. 
Gelfand, M. J., Major, V. S., Raver, J. L., Nishii, L. H., \& O'Brien, K. (2006). Negotiating relationally: The dynamics of the relational self in negotiations. Academy of Management Review, 31(2), 427-451.

Goodwin, M. H. (1990). He-said-she-said: talk as social organization among black children. Bloomington, IN: Indiana University Press.

Greenberg, J., Solomon, S., \& Pyszczynski, T. (1997). Terror management theory of selfesteem and social behavior: Empirical assessments and conceptual refinements. In M. P. Zanna (Ed.), Advances in Experimental Social Psychology (Vol. 29, pp. 61-139). New York, NY: Academic Press.

Grusec, J. E., \& Hastings, P. D. (Eds.). (2007). Handbook of socialization. New York, NY: Guilford.

Gunia, B. C., Brett, J. M., \& Gelfand, M. J. (2016). The science of culture and negotiation. Current Opinion in Psychology, 8, 78-83.

Halevy, N., Y. Chou, E., \& Galinsky, A. D. (2011). A functional model of hierarchy: Why, how, and when vertical differentiation enhances group performance. Organizational Psychology Review, 1(1), 32-52.

Hardy, C. L., Bukowski, W. M., \& Sippola, L. K. (2002). Stability and change in peer relationships during the transition to middle-level school. Journal of Early Adolescence, 22, 117-142.

Kray, L.J. \& Thompson, L. (2005). Gender stereotypes and negotiation performance: an examination of theory and research. In B.M. Staw and R.M. Kramer (Eds.), Research in Organizational Behavior, 26, 103-182.

La Freniere, P., Strayer, F. F., \& Gauthier, R. (1984). The emergence of same-sex affiliative preferences among preschool peers: A developmental/ethological perspective. Child Development, 55, 1958-1965. 
Lax, D. A., \& Sebenius, J. K. (1991). Thinking coalitionally: Party arithmetic, process opportunism, and strategic sequencing. In H. P. Young (Ed.), Negotiation Analysis (pp. 153-193). Ann Arbor, MI: University of Michigan Press.

Lavallee, K. L., \& Parker, J. G. (2009). The role of inflexible friendship beliefs, rumination, and low self-worth in early adolescents' friendship jealousy and adjustment. Journal of Abnormal Child Psychology, 37, 873-885.

Leaper, C. (1994). Exploring the consequences of gender segregation on social relationships. New Directions for Child and Adolescent Development, 65, 67-86.

Lee, S. Y., Kesebir, S., \& Pillutla, M. M. (2016). Gender differences in response to competition with same-gender coworkers: A relational perspective. Journal of Personality and Social Psychology, 110(6), 869-886.

Lever, J. (1976). Sex differences in the games children play. Social Problems, 23(4), 478487.

Lever, J. (1978). Sex differences in the complexity of children's play and games. American Sociological Review, 43, 471-483.

Lynn, R. (1993). Sex differences in competitiveness and the valuation of money in twenty countries. Journal of Social Psychology, 133, 507-511.

Maccoby, E. E. (1988). Gender as a social category. Developmental Psychology, 24, 755765.

Maccoby, E. E. (1990). Gender and relationships: a developmental account. American Psychologist, 4, 513-520.

Maccoby, E. E. (2002). Gender and group process: A developmental perspective. Current Directions in Psychological Science, 11, 54-58. 
Maccoby, E. E., \& Jacklin, C. N. (1987). Gender segregation in childhood. In H. W. Reese (Ed.). Advances in child development and behavior (Vol. 20, pp. 239-288). New York, NY: Academic Press.

MacEvoy, J. P., \& Asher, S. R. (2012). When friends disappoint: boys' and girls' responses to transgressions of friendship expectations. Child Development, 83(1), 104-119.

Maltz, D. N. \& Borker. R. A. (1982). A cultural approach to male-female miscommunication. In J. J. Gumperz (Ed.). Language and social identity (pp. 196-216). Cambridge, England: Cambridge University Press.

Marques, J. M., \& Yzerbyt, V. Y. (1988). The black sheep effect: judgmental extremity towards ingroup members in inter- and intra-group situations. European Journal of Social Psychology, 18, 287-292.

Mayr, U., Wozniak, D., Davidson, C., Kuhns, D., \& Harbaugh, W. (2012). Competitiveness across the life span: the feisty fifties. Psychology and Aging, 27, 278-285.

Miles, E. W., \& Clenney, E. F. (2010). Gender differences in negotiation: A status characteristics theory view. Negotiation and Conflict Management Research, 3(2), $130-144$.

Miller, P. M., Danaher, D. L., \& Forbes, D. (1986). Sex-related strategies for coping with interpersonal conflict in children aged five and seven. Developmental Psychology, 22, 543-548.

Munroe, R. L., \& Romney, A. K. (2006). Gender and age differences in same-sex aggregation and social behavior: A four-culture study. Journal of Cross-Cultural Psychology, 37(1), 3-19.

Niederle, M., \& Vesterlund, L. (2011). Gender and competition. Annual Review of Economics, 3, 601-630. 
Parker, J. G., \& Asher, S. R. (1993). Friendship and friendship quality in middle childhood: Links with peer group acceptance and feelings of loneliness and social dissatisfaction. Developmental Psychology, 29, 611-621.

Parker, J. G., Low, C. M., Walker, A. R., \& Gamm, B. K. (2005). Friendship jealousy in young adolescents: Individual differences and links to sex, aggression, and social adjustment. Developmental Psychology, 41, 235-250.

Parker, J.G. \& Seal, J. (1996). Forming, losing, renewing, and replacing friendships: Applying temporal parameters to the assessment of children's friendship experiences. Child Development, 67, 2248-2268

Pruitt, D. G. (1981). Negotiation behavior. New York, NY: Academic Press.

Ronay, R., Greenaway, K., Anicich, E. M., \& Galinsky, A. D. (2012). The path to glory is paved with hierarchy: When hierarchical differentiation increases group effectiveness. Psychological Science, 23(6), 669-677.

Rose, A. J., \& Asher, S. R. (1999). Children's goals and strategies in response to conflicts within a friendship. Developmental Psychology, 35, 69-70.

Rose, A. J., \& Rudolph, K. D. (2006). A review of sex differences in peer relationship processes: potential trade-offs for the emotional and behavioral development of girls and boys. Psychological Bulletin, 132(1), 98-131.

Ruble, D. N., \& Martin, C. L. (1998). Gender development. In W. Damon (Series Ed.) \& N. Eisenberg (Vol. Ed.), Handbook of child psychology: Vol. 3. Social, emotional, and personality development (5th ed., pp. 933-1016). New York, NY: Wiley.

Savin-Williams, R. C. (1976). An ethological study of dominance formation and maintenance in a group of human adolescents. Child Development, 47, 972-979.

Savin-Williams, R. C. (1979). Dominance hierarchies in groups of early adolescents. Child Development, 50, 923-935. 
Savin-Williams, R. C. (1980a). Social interactions of adolescent females in natural groups. In H.C. Foot, A. J. Chapman, \&J. R. Smith (Eds.), Friendship and social relations in children (pp. 343-364). New York, NY: Wiley.

Savin-Williams, R. C. (1980b). Dominance hierarchies in groups of middle to late adolescent males. Journal of Youth and Adolescence, 9(1), 75-85.

Shulman, S., Laursen, B., Kalman, Z., \& Karpovsky, S. (1997). Adolescent intimacy revisited. Journal of Youth and Adolescence, 26(5), 597-617.

Sidanius, J., Levin, S., Liu, J., \& Pratto, F. (1999). Social dominance orientation, antiegalitarianism and the political psychology of gender: an extension and cross-cultural replication. European Journal of Social Psychology, 30, 41-67.

Small, D.A., Gelfand, M., Babcock, L., \& Gettman, H. (2007). Who goes to the bargaining table? The influence of gender and framing on the initiation of negotiation. Journal of Personality and Social Psychology, 93, 600-613.

Smith, P. K. (1982). Does play matter. Functional and evolutionary aspects of animal and human play. Behavioral and Brain Sciences, 5, 139-184.

Spence, J. T. \& Helmreich R. L. (1983). Achievement-related motives and behaviors. In J. T. Spence (Ed.) Achievement and achievement motives: psychological and sociological approaches (pp.10-74). San Francisco, CA: Freeman.

Stuhlmacher, A. F., \& Linnabery, E. (2013). Gender and negotiation: A social role analysis. In M. Olekalns \& W. Adair (Eds.), Handbook of research on negotiation research (pp. 221-248). London, England: Edward Elgar.

Sutter, M., \& Glätzle-Rützler, D. (2014). Gender differences in the willingness to compete emerge early in life and persist. Management Science, 61, 2339-2354. 
Sutter, M., Glätzle-Rützler, D., Balafoutas, L., \& Czermak, S. (2016). Cancelling out early age gender differences in competition: an analysis of policy interventions. Experimental Economics, 19, 1-21.

Terry, D. J., \& Hogg, M. A. (1996). Group norms and the attitude-behavior relationship: A role for group identification. Personality and Social Psychology Bulletin, 22(8), 776793.

Thorne, B., \& Luria, Z. (1986). Sexuality and gender in children's daily worlds. Social Problems, 33(3), 176-190.

Tiger, L. (1969). Men in groups. New York, NY: Vintage Books.

Van Vugt, M. V., De Cremer, D., \& Janssen, D. P. (2007). Gender differences in cooperation and competition: The male-warrior hypothesis. Psychological Science, 18(1), 19-23.

Watson, C. (1994). Gender versus power as a predictor of negotiation behavior and outcomes. Negotiation Journal, 10, 117-127.

Webb, T. L., \& Sheeran, P. (2006). Does changing behavioral intentions engender behavior change? A meta-analysis of the experimental evidence. Psychological Bulletin, 132, 249-268.

Weiss, D. M., \& Sachs, J. (1991). Persuasive strategies used by preschool children. Discourse Processes, 14(1), 55-72.

Whiting, B. B., \& Edwards, C. P. (1988). Children of different worlds: the formation of social behavior. Cambridge, MA: Harvard University Press. 